\title{
Usefulness of cold polypectomy under linked color imaging $\square$
}

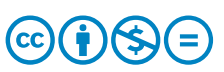

\author{
Authors \\ Institutions \\ 1 Department of Endoscopy, Chiba Cancer Center, Chiba, \\ Japan \\ 2 Department of Gastroenterology, Chiba Cancer Center, \\ Chiba, Japan
}

Takuto Suzuki ${ }^{1}$, Yoshiyasu Kitagawa ${ }^{1}$, Rino Nankinzan ${ }^{1}$, Taketo Yamaguchi ${ }^{2}$

submitted 9.9.2019

accepted after revision 7.10 .2019

Bibliography

DOI https://doi.org/10.1055/a-1035-9411 |

Endoscopy International Open 2020; 08: E87-E91

(c) Georg Thieme Verlag KG Stuttgart · New York elSSN 2196-9736

Corresponding author

Takuto Suzuki, Chiba Cancer Center, 666-2 Nitona-cho, Chuo-ku, Chiba City, Chiba, Japan

Fax: +81-43-262-8680

taksuzuki@chiba-cc.jp

\section{ABSTRACT}

Background and study aims Cold polypectomy is becoming popular for treatment of colon polyps due to its safety and convenience, but there is still the problem of tumor remnants. Because linked color imaging (LCI) improves polyp visibility, cold polypectomy under $\mathrm{LCl}$ is anticipated to reduce the tumor remnant rate. Therefore, we investigated the usefulness of this procedure.

Patients and methods Fifty patients scheduled to undergo cold polypectomy for treatment of colon polyps $<10 \mathrm{~mm}$ and assumed to be adenomas were registered prospectively. After performing cold snare polypectomy (CSP) under $\mathrm{LCl}$, biopsy was performed at two resection margin sites for each polyp to determine the tumor remnant rate.

Results A total of 145 lesions were treated by CSP. Of the 139 lesions in which polyps were retrievable and diagnosed as adenomas pathologically, one lesion was recognized as a remnant adenoma on biopsy (remnant rate: $0.7 \%[95 \% \mathrm{Cl}$ : $0.0-4.4]$ ). This remnant rate was extremely low. Treatment results were extremely promising given that en bloc resection, post-procedure bleeding, and perforation rates were $100 \%, 0 \%$, and $0 \%$, respectively.

Conclusion Cold snare polypectomy under $\mathrm{LCl}$ may be an effective treatment method capable of reducing the tumor remnant rate. This trial was approved by our Institutional Ethics Committee and registered at the University Hospital Medical Information Network (UMIN 000033690).

\section{Introduction}

Colon polyps are regarded as precursor lesions of cancer, and it has been reported that treatment for colon polyps would reduce the number of deaths due to colon cancer [1,2] Conventionally, colon polyps are treated by endoscopic mucosal resection (EMR) and polypectomy using a high-frequency electric device. In these procedures, risk of adverse events (AEs) such as post-procedure bleeding and perforation is not low, and use of an electric device is required [3-5]. Therefore, cold polypectomy is rapidly becoming popular due to its safety and convenience. It has been reported that this procedure is associated with a low rate of AEs such as post-procedure bleeding and perforation and can be performed conveniently within a short period of time [6, 7]. Among the cold polypectomy techniques, CSP is considered to be especially useful for small polyps [8]. How- ever, no burning effect can be anticipated with these procedures because they do not involved use of a high-frequency electric device, and there are concerns about tumor remnants. Some papers have reported remnant rates to be higher with these procedures when compared with those of hot polypectomy or EMR [9-11].

In recent years, image enhanced endoscopy (IEE) has advanced markedly and usefulness of narrow-band imaging (NBI) and blue laser imaging (BLI) in colonoscopy has been reported $[12,13]$. In addition, LCI has been reported to be a new IEE that produces brighter images than NBI or BLI and enables superior visualization of normal polyps, unclear flat lesions, and sessile serrated adenoma polyp (SSAP), leading to a higher lesion detection rate $[10,12,14,15]$. Therefore, we analyzed whether cold polypectomy under $\mathrm{LCl}$ could reduce the tumor remnant rate. 


\section{Patients and methods}

The current study included patients who had been scheduled to undergo CSP from August 2018 to May 2019 for colon polyps $<10 \mathrm{~mm}$, assumed to be adenoma from biopsy or BLI magnifying endoscopy (classified as 2A according to the Japan NBI expert team (JNET) criteria). Protruded type lesions (I p) were excluded to avoid risk of bleeding. Three expert endoscopists performed CSP under $\mathrm{LCl}$, and immediately after the procedure a mucosal biopsy was performed at two margin sites of each resected ulcer to prospectively study the remnant rate. In total, 145 lesions from 50 patients were targeted. Among those lesions, 139 (50 patients) were retrievable polyps, diagnosed as adenoma pathologically, and included in the final analysis ( Fig. 1).

The study protocol was approved by our Institutional Ethics Committee, and registered in the University Hospital Medical Network Clinical Trials Registry (UMIN-CTR, UMIN 000033690). All patients provided their written informed consent before participating in the study.

\section{Linked color imaging}

An endoscopic system with a laser light source (LASEREO, FUJIFILM, Japan) was used. The system included two lasers with different wavelengths. One was a white-light laser (wavelength $450 \pm 10 \mathrm{~nm}$ ) that provided wide-spectrum, white-light illumination suitable for general observation. The other was a BLImode laser (wavelength $410 \pm 10 \mathrm{~nm}$ ) with a short wavelength and a narrow band. The BLI mode delivered high contrast signals which provided information on vessels on the mucosal surface, mucosal irregularities, and deep blood vessels. The intermediate BLI-bright mode, which has a higher white-light intensity ratio, provided a brighter image. The $\mathrm{LCl}$ used in the current study is a novel image-enhanced mode, based on the BLI-bright image, capable of additional image processing and enhances separation of the red color to depict the red and white colors more vividly. Because $\mathrm{LCl}$ enhances color contrast, differences between even light-colored lesions and surrounding tissue were emphasized, thereby facilitating visualization.

\section{Procedure}

As with a regular colonoscopy, pretreatment consisted of oral administration of $10 \mathrm{~mL}$ of $0.75 \%$ sodium picosulfate and $34 \mathrm{~g}$ of magnesium citrate the night before, and $2 \mathrm{~L}$ of polyethylene glycol the morning of the procedure. Examinations and treatments were performed by three experienced endoscopists. After reaching the cecum, the mode was switched to $\mathrm{LCl}$ mode and the scope was removed. After finding the polyps, BLI magnifying endoscopy was performed. If a polyp was considered to be adenoma (JNET classification, type 2A) ( Fig.1), CSP was performed. A 10-mm round snare (SnareMaster Plus, Olympus, Tokyo, Japan) was used for CSP in all cases. During and after CSP, LCl mode was retained. A mucosal biopsy was performed at two resection margin sites (right and left), and the specimen was examined pathologically together with the resected polyp ( $\triangleright$ Video 1 ). When bleeding continued for at least 30 seconds after resection, hemostasis was performed with clip. Due to
Colorectal CSP performed between August 2018 and May 2019 (145 lesions of 50 patients)

- Hyperplastic polyp in pathological finding after CSP (3 lesions)

- Unclear pathological finding due to impossible sample retrieval after CSP (3 lesions)

Lesions diagnosed as adenoma on pathology via CSP (139 lesions of 50 patients)

Biopsy at margins of post CSP ulcer

(139 lesions of 50 patients)

(278 biopsy samples) *2-point biopsy/1 lesion

Pathological identification of residual adenoma (1 lesion [0.7\%; $95 \% \mathrm{Cl} 0.0-3.9 \%]$ )

(1 point $[0.4 \%$; $95 \% \mathrm{Cl} 0.0-2.0 \%]$ )

Fig. 1 Flowchart of patients undergoing cold snare polypectomy (CSP) under linked color imaging (LCI).

the risk of bleeding associated with biopsy, the upper limit was set at five lesions and 10 biopsies for each patient.

\section{Study design}

A tumor remnant rate of $3 \%$ to $6 \%$ after cold polypectomy for colon polyps previously has been reported [9-11]. A remnant rate of $6.8 \%$ has also been reported when a margin biopsy was performed after cold polypectomy similar to this study, and this

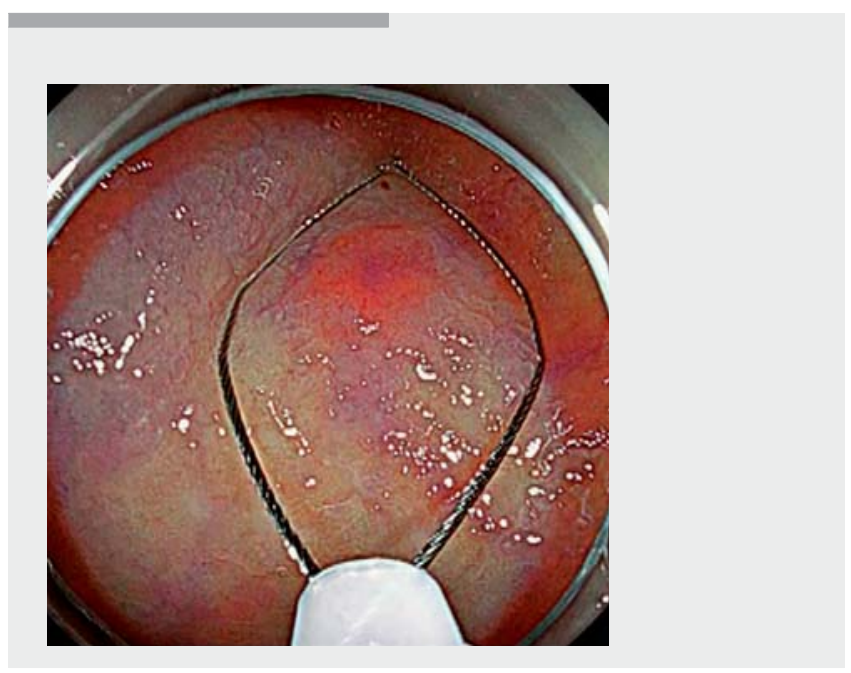

$\checkmark$ Video 1 Cold snare polypectomy (CSP) under linked color imaging $(\mathrm{LCl})$. Snaring of the entire polyp is surely enabled with observing the clarified polyp. 
- Table 1 Patient characteristics.

\begin{tabular}{|l|l|}
\hline Number of patients & 50 \\
\hline Mean age \pm SD, years & $66.7 \pm 9.2$ \\
\hline Median age (range), years & $66(43-86)$ \\
\hline Gender, male (\%) & $33(66.0)$ \\
\hline SD, standard deviation. & \\
\hline
\end{tabular}

- Table 2 Polyp characteristics.

\begin{tabular}{|l|c|}
\hline & $\begin{array}{c}\text { All polyps } \\
\text { (n=145) }\end{array}$ \\
\hline Location, $\mathrm{n}(\%)$ & $9(6.2)$ \\
\hline Cecum & $30(20.7)$ \\
\hline Ascending colon & $49(33.8)$ \\
\hline Transverse colon & $15(10.3)$ \\
\hline Descending colon & $37(25.5)$ \\
\hline Sigmoid colon & $5(3.4)$ \\
\hline Rectum & \\
\hline Size & $5.1 \pm 2.0$ \\
\hline Mean \pm SD, mm & $5(2-10)$ \\
\hline Median (range), mm & \\
\hline Macroscopic appearance, $n(\%)$ & $71(49.0)$ \\
\hline I s & $10(6.9)$ \\
\hline I p & $64(44.1)$ \\
\hline II a & $3(2.1)$ \\
\hline Histological diagnosis, $n$ (\%) & $1(0.7)$ \\
\hline Hyperplastic polyp & \\
\hline Low-grade tubular adenoma & \\
\hline High-grade tubular adenoma & \\
\hline Sessile serrated adenoma & \\
\hline Unknown (not retrieved) & \\
\hline SD, standard deviation. & \\
\hline
\end{tabular}

was used as the reference value. In another procedure, EMR was performed after polypectomy to examine the tumor remnant rate in Japan, and a low tumor remnant rate of $3.9 \%$ was reported. Expecting that the results of this study would be even lower, a tumor remnant rate of $2 \%$ was assumed $[9,11]$. On assuming a significance level (two-sided) ( $\alpha$ value) of 0.05 and a power of test (1- $\beta$ ) of 0.8 , the necessary number of lesions was calculated to be 139 . On assuming that the number of polyps in each patient would be slightly more than three as reported previously, 46 patients were targeted, and the number of patents was set at 50 , assuming a dropout rate of $\sim 10 \%[9-11,16]$.
- Table 3 Treatment results.

\begin{tabular}{|l|l|}
\hline $\begin{array}{l}\text { Residual adenoma, } \mathrm{n}(\%) \\
(95 \% \mathrm{Cl})\end{array}$ & $\begin{array}{l}1(0.7) \\
(0.0-4.4)\end{array}$ \\
\hline $\begin{array}{l}\text { Technical result } \\
\text { En bloc resection, } \mathrm{n}(\%)\end{array}$ & $145(100)$ \\
\hline $\begin{array}{l}\text { Retrieval, } \mathrm{n}(\%) \\
(95 \% \mathrm{Cl})\end{array}$ & $\begin{array}{l}142(97.9) \\
(94.0-99.6)\end{array}$ \\
\hline $\begin{array}{l}\text { Clipping, } \mathrm{n}(\%) \\
(95 \% \mathrm{Cl})\end{array}$ & $\begin{array}{l}3(2.1) \\
(0.4-6.0)\end{array}$ \\
\hline $\begin{array}{l}\text { Adverse events } \\
\text { Delayed bleeding, } \mathrm{n}(\%)\end{array}$ & $0(0)$ \\
\hline Perforation, $\mathrm{n}(\%)$ & $0(0)$ \\
\hline Cl, confidence interval.
\end{tabular}

\section{Statistics}

Clinical data are expressed as percentage, median, and range. Mean and standard deviation (SD) were also calculated. Residual adenoma, retrieval and clipping rates are presented as proportions with $95 \%$ confidence intervals $(\mathrm{Cl})$. Statistical analyses were performed using the Bell Curve for Excel (Social Survey Research Information Co., Ltd.).

\section{Results}

In this study, 145 lesions from 50 patients were resected by CSP ( $\vee$ Table 1 , $\vee$ Table 2 ) According to location, 88 polyps (60.7\%) were found in the right side of the colon, 52 (35.9\%) in the left side of the colon and five $(3.4 \%)$ in the rectum. Mean polyp diameter was $5.1 \pm 2.0 \mathrm{~mm}$ (median value: $5 \mathrm{~mm}$, range: 2 to $10 \mathrm{~mm}$ ). No depressed lesions were found. Three lesions could not be retrieved for pathology. Three hyperplastic polyps were found, and none were cancerous.

\section{CSP outcomes}

- Table 3 shows results of CSP. En bloc resection, sample retrieval, and post-resection clipping rates were 100\%, 97.9\% (95\% Cl: 94.0-99.6), and $2.1 \%(95 \% \mathrm{Cl}: 0.4-6.0)$, respectively. In the three patients who underwent clipping, the polyp had a form of I $p$ and was relatively large (not less than $7 \mathrm{~mm}$ ). No AEs were recognized in any of the patients (post-procedure bleeding rate: $0 \%$, perforation rate: $0 \%$ ).

\section{Remnant after CSP}

In 145 lesions in 50 patients, biopsy was feasible at two sites of each lesion. Among the 139 lesions, excluding the three nonretrievable and three hyperplastic polyps, one lesion was recognized as a remnant adenoma on biopsy (remnant rate: $0.7 \%$ [95\% Cl: 0.0-4.4]) ( $\triangleright$ Table 3). This lesion was located in the transverse colon ( $7 \mathrm{~mm}$, Type Ila), and the pathology revealed low-grade adenoma. In this patient, a repeat endoscopy is planned after a year. 

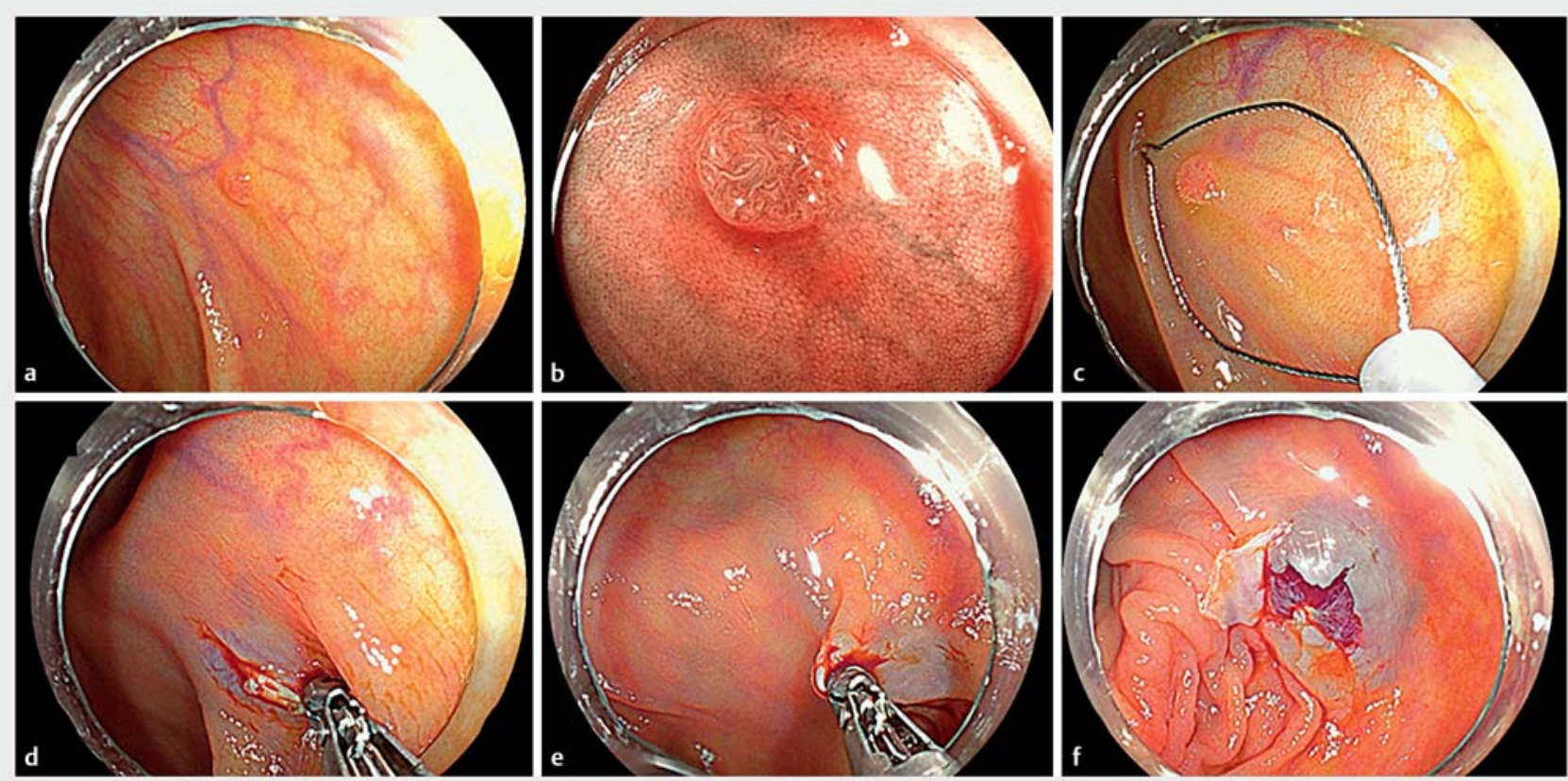

- Fig. 2 Cold snare polypectomy (CSP) of colon polyp. a Colon polyp image by linked color imaging (LCI). b Colon polyp observation by blue laser imaging (BLI) magnification. Adenoma assumed with the finding of $2 \mathrm{~A}$ in JNET classification. c CSP under LCI. $\mathbf{d}$ Biopsy on the right margin side of post-resection ulcer. e Biopsy on the left margin side of post-resection ulcer. $\mathbf{f}$ Ulcer after completion.

\section{Discussion}

In this study, CSP performed using LCI, the new IEE, showed an extremely low tumor remnant rate. We speculate that ability to better visualize polyps by using $\mathrm{LCl}$ contributes to the low remnant rate. In addition, we consider this report to be an extremely rare application of IEE for treatment.

Cold polypectomy is becoming popular for treatment of coIon polyps due to its safety and convenience. This procedure has a very low rate of AEs such as post-therapeutic bleeding and perforation, can be completed in a short time, and is convenient $[6,7]$. In addition, among cold polypectomy procedures, CSP is believed to be particularly useful for small polyps [8]. However, no burning effect can be anticipated with this procedure, and there are bigger concerns about tumor remnants in comparison with hot polypectomy or EMR [9-11]. A study conducted to examine the tumor remnant rate from biopsy after cold polypectomy found that it was $6.8 \%$ after CSP [9]. In the separate but similar study conducted to examine the remnant rate by performing EMR after CSP for polyps $<9$ $\mathrm{mm}$, it was found to be $3.9 \%$ [11]. An adenoma remnant is associated with a risk of recurrence and requires repeat endoscopy, which increases the physical and economic burden to patients. Therefore, it is a task to reduce the tumor remnant rate. $\mathrm{LCl}$ ensures tumor snaring by clarifying demarcation of a small polyp.

Recently, IEE has advanced significantly, and NBI and BLI have been reported to be useful for colonic lesions $[12,13]$. In addition, because it has been reported that $\mathrm{LCl}$ is brighter than $\mathrm{NBI}$ and $\mathrm{BLI}, \mathrm{LCl}$ can improve visualization of normal polyps, un- clear flat lesions, and SSAP; the usefulness of $\mathrm{LCl}$ in comparison to the latter has also been established $[10,12-14]$. Furthermore, in conventional IEE such as NBI and BLI, residues such as feces are red and blood is black. Therefore, when there are residues, the field of vision becomes poor. In addition, if bleeding occurs immediately after resection, the field of vision becomes black, which makes subsequent observation impossible. On the other hand, in case of $\mathrm{LCl}$, residues are yellow and blood is red. Therefore, the field of vision does not become poor even when residues or bleeding are present. A procedure that was typically difficult with IEE when bleeding occurred has become feasible with $\mathrm{LCl}$.

In this study, results of treatment with CSP were extremely promising because the en bloc resection, post-procedure bleeding, and perforation rates were $100 \%, 0 \%$ and $0 \%$, respectively. Furthermore, the adenoma remnant rate could be lowered to $0.7 \%$, which is much lower than conventional rates. A single remnant lesion persisted in the back of haustra of the transverse colon as visualization was difficult at the time of snaring.

There were several limitations to this study. The first was the single-arm design, as there was no group to be compared with directly. Therefore, a randomized controlled trial would be needed in the future. However, multiple reports were used for comparison and the results of this study were considered sufficiently useful. The second limitation was that the tumor remnant rate was determined by biopsy performed after polypectomy at two margin sites and remnant was not checked at other sites. However, previous studies conducted with biopsy and with endoscopic mucosal resection found that the remnant 
rate was not lower in biopsy, so it is considered that the results are acceptable. The third limitation was that this study was conducted in a small number of patients at a single institution. It is necessary to conduct future studies in a larger number of patients at multicenter.

\section{Conclusion}

In conclusion, CSP under $\mathrm{LCl}$ is a method with an extremely low remnant rate of adenoma while being as safe and effective as conventional CSP.

\section{Competing interests}

None

\section{References}

[1] Winawer S], Zauber AG, Ho MN. The National Polyp Study Workgroup. et al. Prevention of colorectal cancer by colonoscopic polypectomy. N Engl J Med 1993; 329: 1977-1981

[2] Zauber AG, Winawer S], O’Brien M] et al. Colonoscopic polypectomy and long-term prevention of colorectal cancer deaths. N Engl J Med 2012; 366: 687-696

[3] Tajiri H, Kitano S. Complications associated with endoscopic mucosal resection: definition of bleeding that can be viewed accidental. Dig Endosc 2004; 16: 134-136

[4] Yamashina T, Takeuchi Y, Uedo $\mathrm{N}$ et al. Features of electrocoagulation syndrome after endoscopic submucosal dissection for colorectal neoplasm. J Gastroenterol Hepatol 2016; 31: 615-620

[5] Oka S, Tanaka S, Kanao $\mathrm{H}$ et al. Current status in the occurrence of postoperative bleeding, perforation and residual/local recurrence during colonoscopic treatment in Japan. Dig Endosc 2010; 22: 376380

[6] Tappero G, Gaia E, De Giuli P et al. Cold snare excision of small colorectal polyps. Gastrointest Endosc 1992; 38: 310-313

[7] Repici A, Hassan C, Vietta E et al. Safety of cold polypectomy for $<10 \mathrm{~mm}$ polyps at colonoscopy: a prospective multicenter study. Endoscopy 2012: 44; 27-31

[8] Takeuchi Y, Yamashina T, Matsuura N et al. Feasibility of cold snare polypectomy in Japan: a pilot study. World J Gastrointest Endosc 2015; 7: 1250-1256

[9] Lee CK, Shim J], Jang JY. Cold snare polypectomy vs. cold forceps polypectomy using double-biopsy technique for removal of diminutive colorectal polyps: A prospective randomized study. Am J Gastroenterol 2013; 108: 1593-1600

[10] Kim JS, Lee B-I, Choi H et al. Cold snare polypectomy versus cold forceps polypectomy for diminutive and small colorectal polyps: a randomized controlled trial. Gastroinest Endosc 2015; 81: 741-747

[11] Matsuura N, Takeuchi Y, Yamasaki T et al. Incomplete resection rate of cold snare polypectomy: a prospective single-arm observational study. Endoscopy 2017; 49: 251-257

[12] Yoshida N, Hisabe T, Hirose R et al. Improvement in the visibility of colorectal polyps by using blue laser imaging. Gastrointest Endosc 2015; 82: 542-549

[13] Horimatsu T, Sano Y, Tanaka S et al. Next-generation narrow band imaging system for colonic polyp detection: 1 prospective multicenter randomized trial. Int J Colorectal Dis 2015; 30: 947-954

[14] Suzuki T, Hara T, Kitagawa Y et al. Linked-color imaging improves endoscopic visibility of colorectal nongranular flat lesions. Gastrointest Endosc 2017; 86: 692-697

[15] Min M, Deng P, Zhang W et al. Comparison of linked color imaging and white-light colonoscopy for detection of colorectal polyps: a multicenter, randomized, crossover trial. Gastrointest Endosc 2017; 86: 724-730

[16] Maruoka D, Arai M, Akizue $\mathrm{N}$ et al. Residual adenoma after cold snare polypectomy for small colorectal adenomas: a prospective clinical study. Endoscopy 2018; 50: 693-700 